\title{
O DESENVOLVIMENTO DA HABILIDADE ORAL ATRAVÉS DO USO DE TECNOLOGIAS DIGITAIS: UMA REVISÃO SISTEMÁTICA
}

\author{
Sâmia Carvalho ${ }^{1^{*}}$ \\ Marjorie Menezes Soares ${ }^{1 * *}$ \\ ${ }^{1}$ Universidade Federal do Ceará, Fortaleza, CE, Brasil
}

\begin{abstract}
Resumo
O presente artigo consiste em uma revisão sistemática da literatura, descritiva-interpretativa, cujo objetivos são (1) apresentar quais abordagens de ensino-aprendizagem são mais utilizadas no desenvolvimento da habilidade oral através de tecnologias digitais; (2) investigar quais ferramentas são mais utilizadas para o desenvolvimento da habilidade oral em ambiente digital; (3) quais aspectos da oralidade estão sendo mais estudados e (4) que possibilidades e restrições são indicadas. Foram analisados 56 trabalhos, entre artigos, dissertações e teses coletados de três bases de dados. As implicações deste trabalho se dão também ao apontar as lacunas de pesquisa na área, tais como a ausência de estudos sobre perspectivas críticas no trabalho com tecnologia e oralidade e a não existência de pesquisas que tratem de como se trabalha a questão da oralidade via TIC na formação inicial e continuada de professores de LE.

Palavras-chave: TIC; Língua Estrangeira; Habilidade Oral
\end{abstract}

\footnotetext{
* Tem especialização em Literatura Estrangeira Moderna (Inglês) pela Universidade Federal do Ceará (1996), possui mestrado em Linguística Aplicada (1999) e doutorado em Linguística Aplicada pela Universidade Estadual do Ceará (2016). Atualmente (2019) é professora efetiva do Magistério - Ensino Básico, Técnico e Tecnológico da Universidade Federal do Ceará. Professora do Programa de Pós-Graduação em Estudos da Tradução (POET). Professora do Curso de Especialização em Linguística Aplicada e Ensino de Língua Estrangeira (CELEST). Atua também como coordenadora e orientadora das disciplinas de estágio de regência no Curso de Licenciatura em Letras: Língua Inglesa e suas Literaturas (modalidade à distância). Tem experiência na área de Ensino de Língua Estrangeira, com ênfase em Métodos e Técnicas de Ensino, atuando principalmente nos seguintes temas: material didático virtual, letramento visual, ensino de inglês como LE, Multimodalidade e Ensino de Inglês - Formação de Professores. E-mail: scarvalho50@gmail.com. ORCID: https://orcid.org/00000002-9915-4442.

"* Licenciada em Letras - Português e Alemão pela Universidade Federal do Ceará (2017), tem especialização em Linguística Aplicada e Ensino de Línguas Estrangeiras pela Universidade Federal do Ceará (2019) e é mestranda em Linguística pela Universidade Federal do Ceará. Atualmente é professora substituta do Magistério Superior na Universidade Federal do Ceará. E-mail: marjoriemms@hotmail.com. ORCID: https://orcid.org/0000-0002$8021-6236$.
} 


\title{
ORAL SKILL DEVELOPMENT THROUGH THE USE OF DIGITAL TECHNOLOGIES: A SYSTEMATIC REVIEW
}

\begin{abstract}
The present article consists of a qualitative, descriptive-interpretative systematic review, whose objectives are (1) to present which teachinglearning approaches are most used in the development of oral skills through digital technologies; (2) investigate which tools are the most used to develop oral skills in digital environment; (3) what aspects of orality are being the most studied and (4) what possibilities and restrictions are indicated. We analyzed 56 papers, among articles, dissertations and thesis collected from three databases. The implications of this work also point to research gaps in the area, such as the absence of studies on critical perspectives in the work with technology and orality, and the lack of research that deals with the question of orality via ICT in the initial and continuing training of LE teachers.
\end{abstract}

Keywords: ICT; Foreign Language; Oral Ability. 


\section{Introdução}

As inovações tecnológicas têm gerado mudanças na forma como nos relacionamos e interagimos. As novas competências necessárias para nos adequarmos a essa nova realidade refletem-se também no ensino-aprendizagem de línguas estrangeiras (doravante, LE). Enquanto os aprendizes estão se tornando mais autônomos e expostos a textos autênticos e a situações reais de uso da LE, os professores procuram inserir recursos tecnológicos em sua sala de aula, usufruindo da oferta de ferramentas que podem servir às mais variadas abordagens de ensino. Isso se deve à necessidade de tornar o processo de ensino-aprendizagem significativo dentro das novas práticas sociais; porém, acompanhar o surgimento de novos aplicativos e plataformas educacionais é um grande desafio, dada a falta de formação tecnológica básica dos educadores e a velocidade na qual a tecnologia evolui atualmente.

O papel do professor ao longo das últimas décadas também sofreu mudanças, passando de aplicador de técnicas a pesquisador da própria prática (CELANI, 2008). A constante atualização do professor de línguas é, portanto, fundamental para que ele consiga se apropriar desses novos paradigmas de ensino no qual o professor deixa de ser o detentor exclusivo do saber e pode exercer novas funções, devido ao grande número de oportunidades de comunicação às quais o aprendiz de LE está exposto no dia a dia. Nesse contexto em que as tecnologias da informação começam a ganhar papel relevante no ensino de LE, é preciso pensar em como promover o aumento das oportunidades de aprendizagem em contextos que integrem as quatro habilidades linguísticas: compreender, falar, escrever e ler. Dentre essas habilidades, segundo Rodrigues e Ortiz-Preuss (2017, p. 73), observa-se que o fenômeno da fala ainda é pouco compreendido e "[...] amplamente guiado pelas percepções e experiências prévias de professores e alunos [...]”. Partimos da hipótese de que há uma aparente limitação tecnológica e didática para a prática da habilidade oral em ambiente digital. Se para o professor é um desafio o desenvolvimento das habilidades de ouvir, ler e escrever em ambiente digital, é um desafio ainda maior o desenvolvimento da habilidade da fala. É justamente nesse contexto desafiador que essa pesquisa se insere e se justifica.

Através de uma revisão sistemática da literatura de caráter descritivo-interpretativo, busca-se apresentar o que pesquisas recentes (2010-2018) apontam em relação ao desenvolvimento da expressão oral através de tecnologias digitais, podendo assim compreender melhor como está se dando esse panorama de mudança no ensino, que antes era restrito ao livro didático e às práticas linguísticas em sala de aula presencial, e agora tem todo um aparato tecnológico digital ao dispor de professores e alunos. Além de iluminar melhor esse cenário de mudança, a presente pesquisa tem o intuito de contribuir com a descoberta de lacunas de pesquisa para que futuros estudos possam focar em elementos ainda não estudados e, dessa forma, possam auxiliar professores e alunos nessa transição do estudo unicamente livresco para um processo de ensino que seja mais condizente com a forma que nos comunicamos na atualidade. 
As questões que norteiam o trabalho são:

- quais abordagens de ensino são mais utilizadas nas pesquisas em ensino de Língua Estrangeira em relação ao desenvolvimento da habilidade oral em ambiente digital?

- quais ferramentas são mais utilizadas para o desenvolvimento da habilidade oral em ambiente digital?

- quais aspectos da oralidade vêm sendo mais estudados através das Tecnologias de Informação e Comunicação (TICs)?

- que possibilidades e restrições são apontadas pelas pesquisas no desenvolvimento da produção oral em LE com tecnologias digitais?

\section{Referencial Teórico}

A análise do corpus da pesquisa parte do levantamento da literatura referente ao tema e divide-se em quatro tópicos: i) Tecnologias de Comunicação e Informação (TICs) e o conceito de Língua Estrangeira (LE); ii) as abordagens e métodos de ensino-aprendizagem: o papel da produção oral e o uso de tecnologias ; iii) aspectos da produção oral; iv) a oralidade e as TICs.

\section{i) Tecnologias de Comunicação e Informação (TICs) e o conceito de Língua Estrangeira (LE).}

A relação do ensino de LE e uso de tecnologias se intensifica na década de 50 com o Método Audiolingual e seus laboratórios de línguas, voltados principalmente para o desenvolvimento da compreensão e produção oral através do uso tecnologias de áudio e imagem. Mais tarde, com a popularização dos computadores, forma-se o campo de estudo em CALL, Computer Assisted Language Learning, definido como "a busca por e o estudo das aplicações do computador no ensino e aprendizado de línguas" (LEVY, 1997, p. 1). O ensino assistido por computador refletia, na época, a visão behaviorista e estruturalista da aprendizagem de línguas do método Audiolingual, no qual a tecnologia, o computador, assumia o papel de tutor que fornecia materiais para prática de exercícios repetitivos (WALKER; WHITE, 2013).

Kern e Warschauer (2000) afirmam que CALL se desenvolveu em três fases - a behaviorista, a comunicativa e a integrativa - seguindo as mudanças de abordagens metodológica no ensino de línguas. Os termos computer e assisted passam a ser repensados e modificados para englobar as novas tecnologias e as novas abordagens e métodos de ensino de LE, resultando no surgimento de outros acrônimos como TELL, Technology Enhanced Language Learning, e ICT, In- 
formation and Communication Technology. Em TELL, as demais tecnologias são consideradas parte do ambiente de aprendizagem e potencializadoras da mesma, englobando teorias estruturalistas, cognitivas e sócio cognitivas de língua (WALKER; WHITE, 2013). Levy e Hubbard (2005), no artigo Why call CALL "CALL", alegam que CALL é um termo consagrado e afirmam que a busca por uma nomenclatura dita mais adequada seria apenas luta por poder e influência. No Brasil, no entanto, ICT torna-se TIC - Tecnologia de Informação e Comunicação - e "é o termo geral utilizado pelas diversas disciplinas e campos de estudo para relatarem suas descobertas" (MARTINS; MOREIRA, 2012, p. 252). Deste modo, por ser um termo que engloba CALL (LEVY; HUBBARD, 2005), utilizaremos o acrônimo TICs para nos referirmos às várias tecnologias que possam vir a ser abordadas na presente revisão sistemática.

Para essa pesquisa, achamos pertinente conceituar Língua Estrangeira, já que alguns autores se utilizam da abreviação L2 para se referir tanto à Segunda Língua quanto à Língua Estrangeira. O conceito de LE pode ser compreendido através da comparação com o de Língua Materna (LM) e Segunda Língua (L2). A LM é a primeira língua com a qual se tem contato, sendo também o idioma falado por um dos pais ou a língua da comunidade. É a língua que se tem mais domínio. A diferença entre a L2 e a LM seria o fato de que as estruturas da primeira língua já estariam consolidadas ao aprender a segunda. Qual seria então a diferença entre a Segunda Língua e Língua Estrangeira? Segundo Ançã (1999, p.15), "língua segunda é língua oficial e escolar, enquanto língua estrangeira, apenas espaço da aula de língua.” Tem-se, portanto, neste trabalho, a L2 como língua de imersão e a LE como língua adquirida em contexto formal de ensino-aprendizagem, como a sala de aula. Muñoz, Araújo e Ceia (2011, p. 13) afirmam ainda que a LE é um termo "reservado [...] a uma língua que não tenha um papel social na comunidade nem presença nos meios de comunicação nessa comunidade [...]". No entanto, podemos dizer que as tecnologias estão proporcionando diferentes contextos nos quais a LE adquire um papel social, como é o caso do inglês e outras línguas na internet.

\section{ii) As abordagens e métodos de ensino-aprendizagem: o papel da produção oral e o uso de tecnologias.}

Para melhor compreensão e análise das ferramentas e das práticas pedagógicas desempenhadas no corpus coletado, levamos em consideração as mudanças dos paradigmas educacionais de ensino de LE e do papel assumido pela habilidade de produção oral ${ }^{1}$ e pelas tecnologias. Não pretendemos, no entanto, traçar um panorama histórico detalhado e sim elencar e comparar aspectos importantes sobre o papel da produção oral dentro das abordagens e métodos ${ }^{2}$ mais relevantes para este trabalho. Leffa (2012) classifica o passado do ensino de línguas como o "domínio do método". A visão de ensino-aprendizagem se baseava em buscar o método ideal de ensino que consistia em técnicas específicas, não necessariamente embasadas em pressupostos teóricos, que poderiam ser aplicadas independen- 
te do contexto, sendo considerado "solução" a todos os problemas do ensino de LE. O Método da Tradução e da Gramática, o Método Direto e o Método Audiolingual são exemplos de métodos que praticamente não se alteraram ao longo do tempo e que ainda são utilizados (RICHARDS; RODGERS, 1986). O Método da Tradução e da Gramática tem como características a aprendizagem através da memorização do léxico e de regras gramaticais, o trabalho com textos literários e sentenças descontextualizadas, a tradução da LE para a LM e o foco na leitura. A oralidade era reduzida ao mínimo, o que ocasionou o surgimento do Método Direto, que, segundo Leffa (2012), viveu à sombra do Método da Tradução e da Gramática até o século 19, quando começou a ganhar destaque pela ênfase na oralidade. Entre as inovações da época, está a fundação da Associação Fonética Internacional, cujo principal objetivo era melhorar o ensino de línguas modernas. A associação defendeu o estudo da língua falada, com enfoque na fonética, e padronizou o Alfabeto Fonético Internacional, criado em 1886. No Método Direto, a pronúncia era enfatizada e as habilidades orais deviam ser aprendidas através do professor, falante nativo, e da progressão gradual e mecânica de perguntas e respostas entre professor-alunos e alunos-alunos. Pela proibição do uso da LM, os professores enfrentavam problemas em explicar palavras sem utilizar a tradução, resultando em momentos de frustração para professores e alunos. No início do século 20 , estudos concluíram que não havia método perfeito e abordagens diversas passaram a surgir, porém, voltadas para a linguagem escrita. Esse panorama perdurou até a Segunda Guerra Mundial (RICHARDS; RODGERS, 1986), quando a oralidade se tornou de extrema importância.

No período da Segunda Guerra Mundial, houve a necessidade de se ensinar LEs aos soldados americanos, surgindo então a área de Linguística Aplicada ao Ensino de LE, com soluções apoiadas em teorias científicas vigentes e no uso de tecnologias para o ensino-aprendizagem rápido de línguas (RODRIGUES; CERUTTI-RIZZATTI, 2011). Sob influência da psicologia behaviorista de Watson e Skinner, que consistia no condicionamento da aprendizagem através de estímulos e respostas, e das teorias linguísticas estruturalistas, a oralidade passou a ser praticada através da repetição de modelos de diálogos, sendo os erros evitados, assim como a língua materna, para que houvesse a interiorização "correta" das estruturas linguísticas. A ênfase era dada na pronúncia e na entonação e as tecnologias audiovisuais ganharam bastante relevância no ensino com o surgimento de laboratórios, onde a compreensão e a produção oral eram praticadas. Os exercícios consistiam em escutar um áudio e fornecer respostas orais aos exercícios de gramática e pronúncia. As respostas podiam ser gravadas; no entanto, não havia feedback das produções orais, estas tendo de serem feitas pelo próprio aluno com base no modelo apresentado.

Berdugo (2001) denomina esse período de condutista-estruturalista, que foi seguido pelo período cognitivista-comunicativo e, posteriormente, pelo período sociocognitivista-comunicativo. A autora faz uma síntese dos desenvolvimentos tecnológicos, princípios e teorias de aprendizagem e teorias linguísticas e as aplicações do Ensino de Línguas Assistido por Computador (E.L.A.C.), assinalando 
que essas aplicações de tecnologia estavam voltadas, na época, para o sistema tutorial de criação de drills e programas de exercícios de tipo estrutural.

Contrapondo-se à visão até então, na qual o aluno era passivo no processo de ensino-aprendizagem, surgem teorias da psicologia cognitiva e da linguística gerativa de Chomsky, que, com a noção de competência e desempenho, dão base a novas abordagens. A linguagem passa a ser vista como um sistema análogo ao computacional no qual as informações são armazenadas, reestruturadas e ativadas. Hymes (1972), apesar de apontar a superioridade do paradigma competência-desempenho em relação ao paradigma langue-parole de Saussure - dado que a terminologia prevê "pessoas concretas, situações e ações" (HYMES, 1972, p. 273) -, frisa que até então o componente social, o contexto, havia sido depreciado e negligenciado. As comunidades de fala não seriam homogêneas no que diz respeito ao uso da língua, propondo então o conceito de competência comunicativa, definida de modo sucinto como conhecimento das regras de uso da língua. Desta forma, segundo Austin (1990, p. 10), temos que "investigar o contexto social e cultural no qual [a língua] é usada, as práticas sociais, os paradigmas e valores, a 'racionalidade', enfim, desta comunidade, elementos estes dos quais a linguagem é indissociável". A teoria construtivista de Piaget, na qual o ambiente físico e social oferece oportunidades de interação entre o sujeito e o objeto para gerar aprendizagem, processo no qual o professor é mediador e o aluno é ativo na construção de seu conhecimento, também embasa essa nova perspectiva.

Essas visões sobre linguagem e ensino-aprendizagem foram aplicadas ao ensino de LE gerando a Abordagem Comunicativa, que teve um grande impacto no ensino de línguas ao conceber a língua como evento comunicativo e propondo a integração das quatro habilidades comunicativas, a imersão e a interação na LE e o uso de materiais autênticos.

As tecnologias passam então a simular a realidade para desencadear os processos cognitivos e desenvolver as competências dos alunos, surgindo assim, no período cognitivista-comunicativo, os micromundos lúdicos, que visavam à aprendizagem de línguas através de resolução de problemas e teste de hipóteses (BERDUGO, 2001), seguindo a teoria do input compreensível de Krashen (1985), na qual a aprendizagem se daria através da compreensão de mensagens que estão um pouco acima da nossa competência, tendo o contexto o papel de ajudar no entendimento das estruturas ainda não adquiridas. No entanto, os softwares disponíveis possibilitavam apenas uma interação comunicativa ilusória na qual não havia uma negociação de sentido efetiva (KERN; WARSCHAUER, 2000). Não existiam programas capazes de oferecer o feedback do discurso escrito ou falado dos usuários, o que levava apenas à prática das habilidades receptivas de leitura e compreensão oral.

Em oposição à hipótese do input de Krashen (1985), Swain (1985) formula a hipótese do output, segundo a qual a aprendizagem de LE se realizaria através da produção oral e escrita, ressaltando a necessidade do professor de fornecer aos alunos oportunidades para praticar a oralidade e, assim, receber feedbacks, implícitos ou explícitos, modificando e reprocessando o output. Ao mesmo tempo, a teoria sociointeracionista de Vygotsky, na qual a aprendizagem é um processo de 
construção social, apontando a importância da interação para o desenvolvimento cognitivo, passa também a ganhar relevância. Através dos avanços tecnológicos e das teorias que enfatizam a interação significativa em comunidades discursivas autênticas, o computador começa a ser visto como ferramenta de comunicação com o mundo (KERN; WARSCHAUER, 2000). Segundo Berdugo (2001), neste período denominado sociocognitivista-comunicativo, há uma ênfase no ensino de línguas baseado nas habilidades integradas, em tarefas ou projetos, na aprendizagem telecolaborativa e em redes. O computador é concebido como tutor e ferramenta que estimula o ensino-aprendizagem, compondo um sistema de cursos multimídias, servidores de informação e mensagens eletrônicas sincrônicas e assíncronas.

Atualmente vivemos no "domínio do pós-método" (LEFFA, 2012). O conceito da pedagogia pós-método é definido por Kumaravadivelu (2001) a partir dos parâmetros pedagógicos da particularidade, praticidade e possibilidade. A particularidade diz respeito ao desenvolvimento da consciência crítica relacionada ao contexto de ensino, onde deve-se considerar os aspectos socioculturais, políticos e linguísticos locais, que refletem diretamente nos objetivos e barreiras da aprendizagem. No entanto, normalmente, são apresentadas aos professores teorias que não condizem com as particularidades do seu contexto, havendo uma distinção clara entre teoria e prática. O parâmetro pedagógico da praticidade aponta a importância das experiências e intuições dos professores para formular suas próprias teorias que possam concretizar a aprendizagem em sua sala de aula, superando as deficiências de princípios abstratos. Para isso, os professores precisam desenvolver capacidades reflexivas para identificar e resolver problemas. A pedagogia da possibilidade remonta ao educador Paulo Freire, que afirma que toda pedagogia envolve relações de poder e dominância.

Se faz necessário, desse modo, considerar não apenas o ambiente da aula, mas também as forças sociopolíticas externas, de forma a não reproduzir desigualdades sociais. O aluno, no pós-método, é um aprendiz com autonomia acadêmica, monitora sua própria aprendizagem, com autonomia social, habilidade de cooperar com outros membros da comunidade, e com autonomia libertadora, capaz de mudar sua realidade (KUMARAVADIVELU, 2001). Essa abordagem crítica nos leva também à abordagem pós-moderna da interculturalidade nas aulas de LE. Nesta abordagem, denominada também de ecológica, o ensino de cultura enfatiza a

relação entre o eu e o outro ao longo de múltiplas escalas de tempo numa perspectiva descentralizada, em que o significado dos eventos surge de forma não linear por meio de interações com outros, e a realidade social é construída a cada minuto no discurso contínuo. Nessa perspectiva, os alunos de línguas não mudam a sua identidade ao aprender uma língua estrangeira, mas podem ser levados a mudar as posições do sujeito. (KRAMSCH, 2017, p. 144)

As posições do sujeito constituem a cultura, que é concebida como prática discursiva. Segundo Kramsch (2017, p. 146), "aprender sobre uma cultura estrangeira sem estar ciente de suas próprias práticas discursivas pode levar a uma com- 
preensão ahistórica e anacrônica do Outro e a um entendimento básico e, por conseguinte, limitado do Eu". Devido à propagação e acessibilidades das TICs, é possível interagir síncrona e assincronamente com pessoas de diversos países e backgrounds culturais, facilitando o desenvolvimento não só da habilidade oral como também o desenvolvimento da competência intercultural.

A noção de aprendizagem em rede possibilitada pelas TICs aponta também para o Conectivismo de Siemens (2004), teoria na qual as conexões criadas com outras pessoas e fontes de informação são fundamentais para construção de conhecimento, reconhecendo-o em sua natureza fluida, produto da era digital.

A aprendizagem é um processo que ocorre dentro de ambientes nebulosos onde os elementos centrais estão em mudança. A aprendizagem (definida como conhecimento acionável) pode residir fora de nós mesmos (dentro de uma organização ou base de dados), é focada em conectar conjuntos de informações especializados, e as conexões que nos capacitam a aprender mais são mais importantes que nosso estado atual de conhecimento (SIEMENS, 2004, p. 5)

Essa aprendizagem em ambiente digital, no entanto, tem que ser concebida em seu contexto sociocultural de veiculação, no qual são disseminadas ideologias. Chapelle (2003) propõe, desse modo, uma perspectiva com base na junção de três visões sobre tecnologia e suas implicações para o ensino de línguas estrangeiras.

Quadro 1 - Sumário de três perspectivas sobre tecnologia e implicações para o ensino de línguas

\begin{tabular}{|l|l|l|l|}
\hline Visão & Foco em... & Perspectiva & $\begin{array}{l}\text { Implicação para o Ensino } \\
\text { de Línguas }\end{array}$ \\
\hline Tecnologista & $\begin{array}{l}\text { Potenciais } \\
\text { tecnológicos } \\
\text { Rápidos avanços } \\
\text { tecnológicos sugerem } \\
\text { acesso abrangente e } \\
\text { uso de tecnologia que } \\
\text { resultam em um estilo } \\
\text { de vida high-tech. }\end{array}$ & $\begin{array}{l}\text { Professores e pesquisa- } \\
\text { dores devem ser instruí- } \\
\text { dos sobre possibilidades } \\
\text { que possam melhorar ou } \\
\text { mudar seu trabalho. }\end{array}$ \\
\hline $\begin{array}{l}\text { Social } \\
\text { pragmática }\end{array}$ & $\begin{array}{l}\text { Práticas } \\
\text { humanas } \\
\text { tecnologia }\end{array}$ & $\begin{array}{l}\text { Tecnologias imperfei- } \\
\text { tas e práticas humanas } \\
\text { normais de trabalho } \\
\text { restringem o uso da } \\
\text { tecnologia. }\end{array}$ & $\begin{array}{l}\text { Professores e pesquisa- } \\
\text { dores devem analisar } \\
\text { cuidadosamente suas } \\
\text { opções reais em vista da } \\
\text { experiência de outros e } \\
\text { seus próprios contextos e } \\
\text { experiências. }\end{array}$ \\
\hline $\begin{array}{l}\text { Crítica } \\
\text { analista }\end{array}$ & $\begin{array}{l}\text { Implicações } \\
\text { de valor da } \\
\text { tecnologia }\end{array}$ & $\begin{array}{l}\text { A tecnologia não é neu- } \\
\text { tra e inevitável. }\end{array}$ & $\begin{array}{l}\text { Professores e pesquisa- } \\
\text { dores devem ser cientes } \\
\text { criticamente da conexão } \\
\text { entre tecnologia e ideo- } \\
\text { logias culturalmente } \\
\text { vinculadas. }\end{array}$ \\
\hline
\end{tabular}

Fonte: Chapelle (2003, p. 10). 
Adotaremos, desse modo, a perspectiva proposta por Chapelle para análise dos trabalhos, visto que há a necessidade de um "pragmatismo crítico e tecnologicamente informado para ajudar profissionais da linguística aplicada a navegar nesse ambiente complexo" (CHAPELLE, 2003, p. 2), que é o ensino de LE através de tecnologias digitais.

\section{iii) Aspectos da produção oral}

Como apontado anteriormente, partimos da hipótese de que há uma aparente limitação tecnológica e didática para a prática da habilidade oral em ambiente digital. Precisamos, pois, compreender como se dá o desenvolvimento da referida habilidade, desde o processamento da fala aos tipos de interação promovidos pelas tecnologias digitais.

A fala consiste em uma habilidade que envolve complexos processos cognitivos - linguísticos e conceituais - e conhecimento de padrões pragmáticodiscursivos (LEVELT, 1989). Levelt (1999) propõe um modelo de processamento da fala, que será utilizado para análise do corpus deste trabalho, no qual há uma preparação conceitual, codificação gramatical e articulação fonética, resultando na expressão da fala, que monitoramos, reiniciando o processo. De acordo com o modelo, na preparação conceitual (conceptual preparation) exercitamos nossa competência social ao nos prepararmos para formular uma mensagem considerando o conhecimento compartilhado com o interlocutor, de modo a direcionar sua atenção para uma informação específica. Na codificação gramatical (grammatical encoding), o falante formula um padrão sintático apropriado, a estrutura de superfície (surface structure), através da ativação dos lemas no léxico mental. A partir dessa ativação, a composição morfo-fonológica (morpho-phonological encoding) se torna acessível e possibilita a divisão silábica adequada ao contexto sintático. $\mathrm{Na}$ articulação fonética (phonetic encoding) é acionado para cada sílaba um gesto articulatório que é executado na articulação (articulation) em si, resultando na expressão da fala (overt speech). Nós monitoramos então nosso output (self-perception) e, quando percebemos falhas comunicativas, nós podemos nos corrigir, reiniciando o processo (LEVELT, 1999). Como o falante precisa estar atento ao que quer dizer, a conceitualização e a formulação podem ser apenas parcialmente automatizadas. "A automatização é necessária devido à capacidade limitada de atenção, que dificulta o controle consciente e simultâneo da conceitualização, da formulação e da articulação" (PREUSS, 2014, p. 6).

A competência comunicativa oral pode então se tornar um desafio para os aprendizes de LE, dado que a fala é dinâmica e a espontaneidade e a rapidez da maioria das interações dificultam o planejamento das construções (CRYSTAL, 2001), podendo gerar ansiedade e nervosismo. 


\section{iv) A oralidade e as TICs}

Crystal (2001), em seu livro Language and the Internet, discorre sobre a linguagem utilizada na Internet analisando a comunicação mediada por tecnologia. Para exemplificar as mudanças que estão ocorrendo, o autor primeiramente descreve a língua falada e a escrita. A língua falada é caracterizada como limitada ao tempo, espontânea, face a face, socialmente interativa, informalmente estruturada, imediatamente revisável e rica em prosódia. Enquanto a linguagem escrita é limitada ao espaço, artificial, visualmente descontextualizada, factualmente comunicativa, estruturalmente elaborada, repetidamente revisável e graficamente rica. Sendo a Internet um meio predominante de textos escritos, nota-se, no entanto, que em vários gêneros digitais escritos há traços da oralidade. Crystal refere-se a essa linguagem, que possui propriedades da língua escrita e falada, como Netspeak. No entanto, segundo o autor, há várias diferenças em relação ao Netspeak e a interação face a face, até mesmo em situações eletrônicas que se assemelham à fala. A primeira diferença diz respeito à falta de feedback simultâneo e a segunda ao ritmo claramente mais lento de interação via Internet. Até mesmo em situações de interação síncrona, em videoconferências e mundos virtuais, o ritmo pode ser afetado por lags (retardos de tempo), ocasionados por problemas na conexão, superlotação na rede e o próprio equipamento dos usuários, podendo gerar frustração e mal-entendidos. Os lags afetam as tomadas de turno gerando muitas vezes situações imprevisíveis e desconexas também em chats e e-mails. As situações de interação na Internet são divididas por Crystal em quatro categorias: e-mail, grupos de chat, mundos virtuais e World Wide Web (WWW). O e-mail transfere mensagens de forma assíncrona e apresenta uma estrutura discursiva fixa. Esse meio de comunicação pode ser considerado limitado devido à falta de controle sobre ele após enviado. Não conseguimos, por exemplo, nos assegurar se ele foi lido ou editado. Os chats, por outro lado, se mostram mais flexíveis, proporcionando tanto conversas síncronas, quanto assíncronas. Os grupos podem ser globais ou locais, permitindo a exposição a uma grande diversidade linguística. Os mundos virtuais possibilitam uma rica interação por meio do espaço virtual compartilhado, do role-play e da criação de sessões de chat. Os avanços tecnológicos permitem, por exemplo, que jogadores de várias partes do mundo interajam oralmente durante um jogo. A World Wide Web é definida pelo autor como "a coleção completa de todos os computadores conectados à Internet que guardam documentos que são mutualmente acessíveis através do uso de um protocolo padrão" (CRYSTAL, 2001, p. 13). A Web permite a interação multimídia entre usuários de dispositivos eletrônicos no mundo todo. No entanto, Marcuschi (2010, p.19) ressalva que, apesar de Crystal reconhecer a mudança das práticas sociais com o advento da Internet, ele "pouco se dedicou a uma análise dos aspectos centrais implicados pelas inovações trazidas aos modos de interagir" e complementa afirmando que há a necessidade de um estudo etnográfico mais aprofundado da comunicação nesse meio. 


\section{Metodologia}

O presente trabalho consiste em uma revisão sistemática da literatura de caráter descritivo-interpretativo. A revisão sistemática da literatura se diferencia de uma revisão bibliográfica, ou narrativa, por ser mais que um breve resumo de trabalhos realizados dentro do problema de pesquisa levantado. Ela pode ser definida como "uma metodologia rigorosa proposta para identificar os estudos sobre um tema em questão, aplicando métodos explícitos e sistematizados de busca; avaliar a qualidade e validade desses estudos, assim como sua aplicabilidade" (DE -LA-TORRE-UGARTE-GUANILO; TAKASHI; BERTOLOZZI, 2011, p. 1261). Os passos a serem seguidos, de acordo com Castro (2001) são: (1) formulação da pergunta; (2) localização e seleção dos estudos; (3) avaliação crítica dos estudos; (4) coleta dos dados; (5) análise e apresentação dos dados; (6) interpretação dos dados; (7) aprimoramento e atualização da revisão sistemática. A constituição do corpus desta pesquisa foi realizada de acordo com as seguintes etapas:

Quadro 2-Critérios de localização e seleção dos estudos.

\begin{tabular}{|c|c|c|}
\hline Etapas & Critérios de inclusão & $\begin{array}{l}\text { Critérios de } \\
\text { exclusão }\end{array}$ \\
\hline \multirow[t]{4}{*}{$\begin{array}{l}\text { Identificação } \\
\text { da literatura }\end{array}$} & $\begin{array}{l}\text { Data de publicação: } \\
2010 \text { - } 2018 \text {. }\end{array}$ & \\
\hline & Idiomas: português e inglês. & \\
\hline & $\begin{array}{l}\text { Bases de Dados: BDTD, periódicos CAPES } \\
\text { e Google Acadêmico (busca avançada } \\
\text { intitle:"palavra-chave 1", "palavra-chave 2" } \\
\text { "palavra-chave 3"). }\end{array}$ & \\
\hline & $\begin{array}{l}\text { Palavras-chave de pesquisa: } \\
\text { produção oral/ oralidade/ habilidades } \\
\text { orais/ ensino/ aprendizagem/ ensino- } \\
\text { aprendizagem/ tecnologias digitais/TIC/ } \\
\text { internet/ ferramenta digital/ LE/ língua } \\
\text { estrangeira; } \\
\text { oral production/oral skills/ speaking/ } \\
\text { teaching/ learning/ teaching-learning/ } \\
\text { technology/ CALL/ TELL / internet/ digi- } \\
\text { tal tool/ FL/ foreign language/ }\end{array}$ & \\
\hline Triagem & $\begin{array}{l}\text { Conter no título e/ou resumo combinação } \\
\text { de palavras-chave referentes a tecnologia, a } \\
\text { ensino e aprendizagem de línguas estrangei- } \\
\text { ras e a produção oral. }\end{array}$ & $\begin{array}{l}\text { Títulos e/ou Resumos } \\
\text { não correspondentes à } \\
\text { questão de pesquisa e } \\
\text { trabalhos duplicados. }\end{array}$ \\
\hline Elegibilidade & Acesso, atualidade e autenticidade. & \\
\hline
\end{tabular}

Fonte: elaborado pela autora.

No quadro 3 a seguir apresentamos as etapas que percorremos na constituição do corpus. 
Quadro 3 - Constituição do corpus.

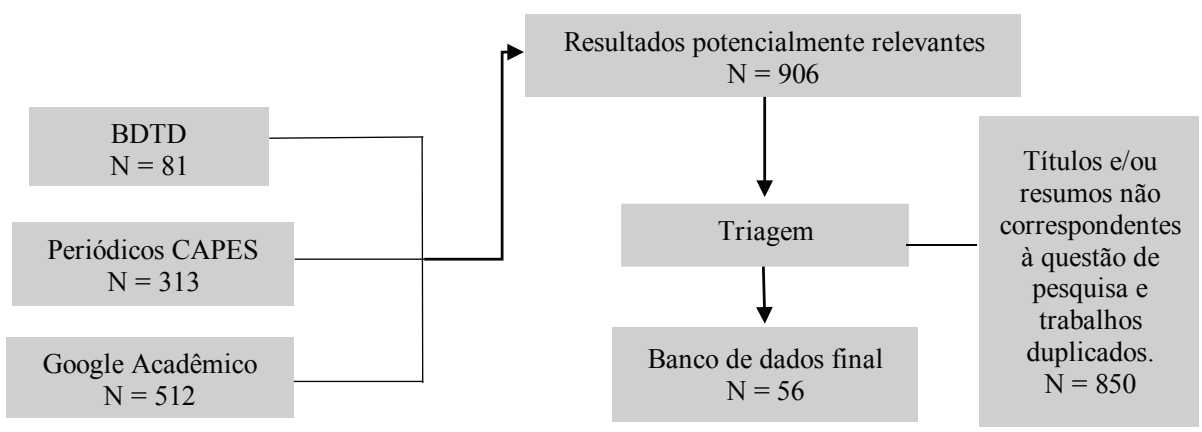

Fonte: dados da pesquisa.

Após a seleção dos 56 trabalhos, entre artigos, dissertações e teses publicados entre 2010 e 2018, a revisão ocorreu através de síntese, análise e interpretação dos dados de modo a responder às questões de pesquisa. A análise do conteúdo se deu através da topicalização do corpus em categorias de análise: (1) data; (2) Língua Estrangeira; (3) tipo de trabalho acadêmico; (4) objetivos; (5) tipo de comunicação; (6) tecnologias empregadas; (7) quadros teóricos de referência - abordagens ou métodos de ensino-aprendizagem, perspectivas do uso das tecnologias e habilidade oral; (8) resultados e implicações. A interpretação dos dados foi realizada de modo a identificar pontos de convergência, avaliar os resultados dos trabalhos, verificar problemas não solucionados e sistematizar os problemas de pesquisa.

\section{Apresentação e interpretação dos dados}

A data de publicação dos trabalhos é considerada um critério importante quando se trata de tecnologia. As ferramentas digitais podem desaparecer ou sofrer alterações, seguindo a lógica da teoria de Siemens (2004) acerca da fluidez e da complexidade do meio virtual. Percebemos uma certa instabilidade na tendência de publicação de trabalhos voltados para a produção oral através do uso de TICs. No começo da década houve um pico de publicação que está sendo retomado após uma brusca queda em 2017, conforme o gráfico a seguir.

Gráfico 1 - Ano de publicação dos trabalhos analisados.

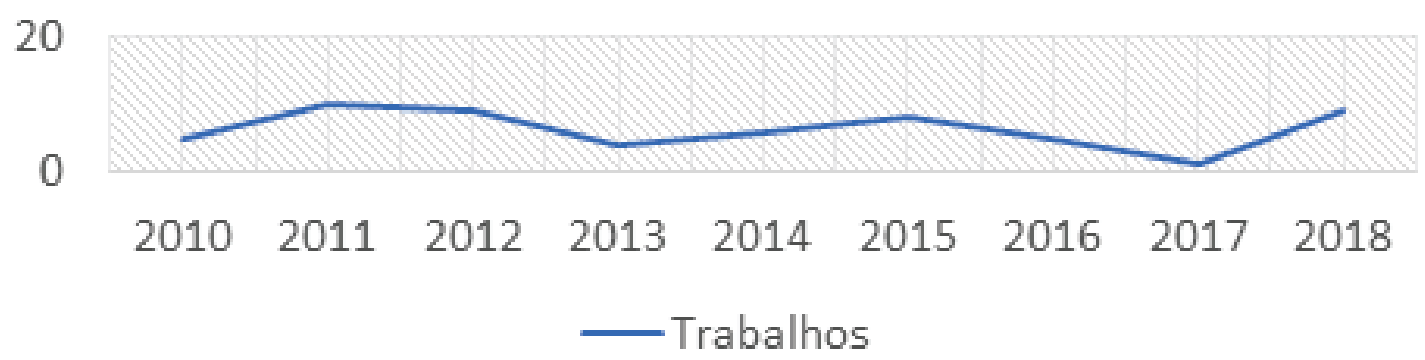

Fonte: dados da pesquisa. 
Pesquisas sobre inglês como língua estrangeira constituem a maior parte do nosso corpus (56\%) assim como artigos acadêmicos (72\%).

Gráfico 2 - Línguas Estrangeiras pesquisadas.

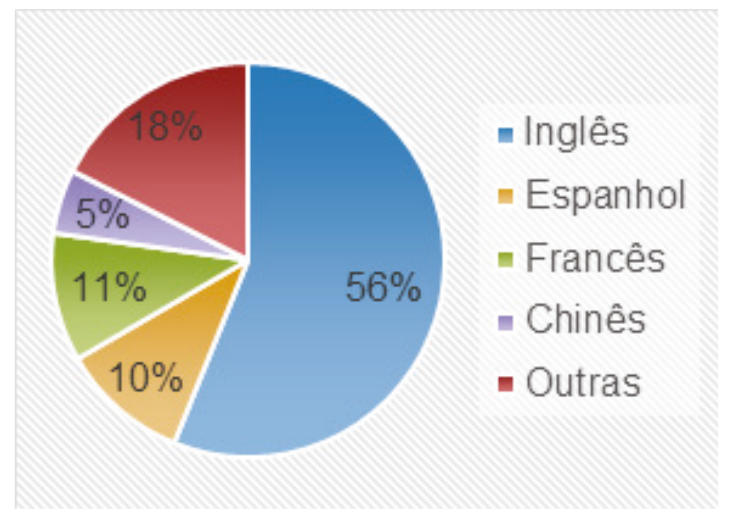

Gráfico 3 - Tipos de trabalhos acadêmicos analisados.

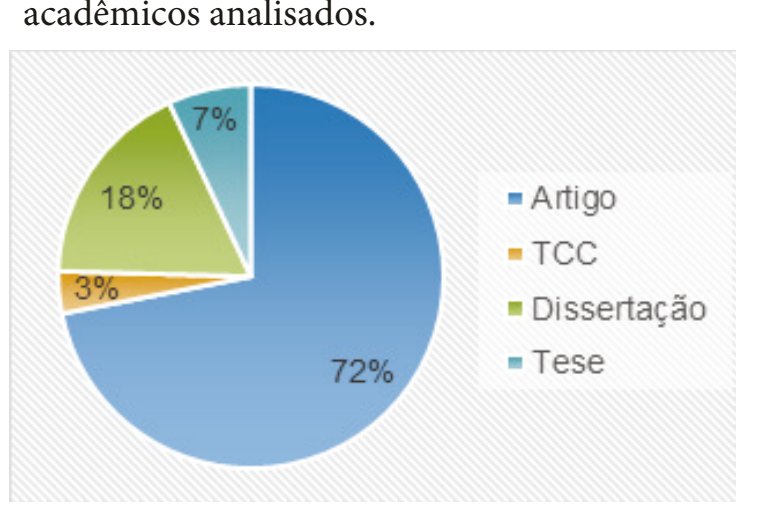

Fonte: dados da pesquisa.

A sistematização dos dados, como apontado anteriormente, partiu da organização dos objetivos gerais, que foram simplificados para uma categoria maior na qual fosse possível compartimentar os trabalhos e identificar os principais interesses das pesquisas desenvolvidas.

Quadro 4 - Objetivos.

\begin{tabular}{|l|l|l|}
\hline \multirow{2}{*}{ Objetivos gerais } & \multicolumn{2}{|l|}{$\begin{array}{l}\text { Quantidade de trabal- } \\
\text { hos }\end{array}$} \\
\hline $\begin{array}{l}\text { Investigar e descrever aspectos metodológicos do en- } \\
\text { sino com TICs. }\end{array}$ & Português & Inglês \\
\cline { 2 - 3 } & 1 & 6 \\
\hline $\begin{array}{l}\text { Verificar a eficácia do uso de ferramentas digitais na } \\
\text { prática oral. }\end{array}$ & 8 & 8 \\
\hline $\begin{array}{l}\text { Analisar o ensino promovido através do uso de fer- } \\
\text { ramentas para prática da oralidade no EaD no ensino } \\
\text { semipresencial. }\end{array}$ & 16 & \\
\hline Desenvolver a oralidade por meio do uso das TICs & 12 & 5 \\
\hline
\end{tabular}

Fonte: dados da pesquisa.

O primeiro objetivo abrange trabalhos explanatórios e considerações teórico-metodológicas acerca do uso das tecnologias digitais no ensino-aprendizagem de línguas estrangeiras com foco na oralidade. Já no segundo, encontram-se pesquisas com a finalidade de testar e analisar a eficácia do uso de ferramentas digitais na prática oral através, principalmente, de pesquisa-ação ou estudo de caso. O terceiro objetivo pertence a trabalhos de metodologias variadas voltados para a análise do ensino-aprendizagem de cursos e ferramentas no e-learning e no b-learning (blended learning); no entanto, a maioria das pesquisas são voltadas apenas ao ensino a distância. No quarto objetivo, nos deparamos com trabalhos 
que visam principalmente apenas desenvolver a oralidade em si, diferenciandose dos anteriores por não se proporem a uma análise mais geral das metodologias de ensino com as TICs, nem analisar a fundo as ferramentas escolhidas e por não focarem no ensino a distância ou semipresencial, utilizando-se de ferramentas digitais em sala de aula. Foi feita uma comparação de pesquisas desenvolvidas por língua pesquisada para que se pudesse estabelecer uma comparação de interesses dos pesquisadores da área. Percebemos a diferença dos interesses de pesquisadores de universidades estrangeiras, que consistem nos trabalhos de língua inglesa, em relação ao foco metodológico e à análise de ferramentas. As pesquisas das universidades brasileiras e portuguesas se dedicam principalmente à produção oral no EaD - assim como no ensino semipresencial - e apenas um trabalho traz considerações teórico-metodológicas sobre a referida habilidade. Segundo as pesquisas analisadas, esse fato é reflexo da ampliação de demanda dos cursos à distância e da necessidade de se usar as TICs para avaliação da oralidade e para promover a interação oral entre, principalmente, aluno e professor. Apesar de estudos não se voltarem à formação de professores para o uso de tecnologia, a maioria deles foram desenvolvidos em disciplinas de língua e cultura estrangeiras de cursos de Licenciatura em Letras.

Em relação ao tipo de comunicação promovida pelas pesquisas, percebe-se uma predominância das práticas assíncronas, conforme o gráfico abaixo.

Quadro 5 - Tipos de Comunicação.

\begin{tabular}{|l|l|}
\hline Síncrona & $22 \%$ \\
\hline Assíncrona & $59 \%$ \\
\hline Síncrona e Assíncrona & $9 \%$ \\
\hline Não especificada & $10 \%$ \\
\hline
\end{tabular}

Fonte: dados da pesquisa.

A preferência por ferramentas assíncronas se justifica pelo maior controle das interações, da produção oral - desenvolvimento de estratégias metacognitivas - e do feedback fornecido aos alunos, assim como a possibilidade de flexibilidade temporal-espacial. A comunicação assíncrona, desse modo, auxilia principalmente na preparação conceitual, articulação fonética e no monitoramento da fala, segundo o modelo proposto por Levelt (1999). Já a comunicação síncrona é utilizada para promover a fluência, ou seja, a expressão da fala, e situações semelhantes à face-a-face, envolvendo aspectos afetivo-emocionais. O uso de ambos os tipos - síncrona e assíncrona - aborda tanto os processos de conceitualização quanto de formulação e de articulação, podendo conduzir os estudantes à automatização da fala em LE. No entanto, os dados mostram que esse uso é ainda pouco explorado.

As ferramentas digitais utilizadas foram divididas segundo as situações de interação na internet propostas por Crystal (2001). Ressaltamos, porém, que nem todas as ferramentas utilizadas foram categorizadas devido à necessidade de 
atualização dos tipos de situações promovidas e a pouca frequência com que foram utilizadas dentro da categoria World Wide Web, como discutiremos a seguir.

Quadro 6 - Situações de interação na Internet, baseadas em Crystal (2001), em relação ao número de trabalhos que as abordam.

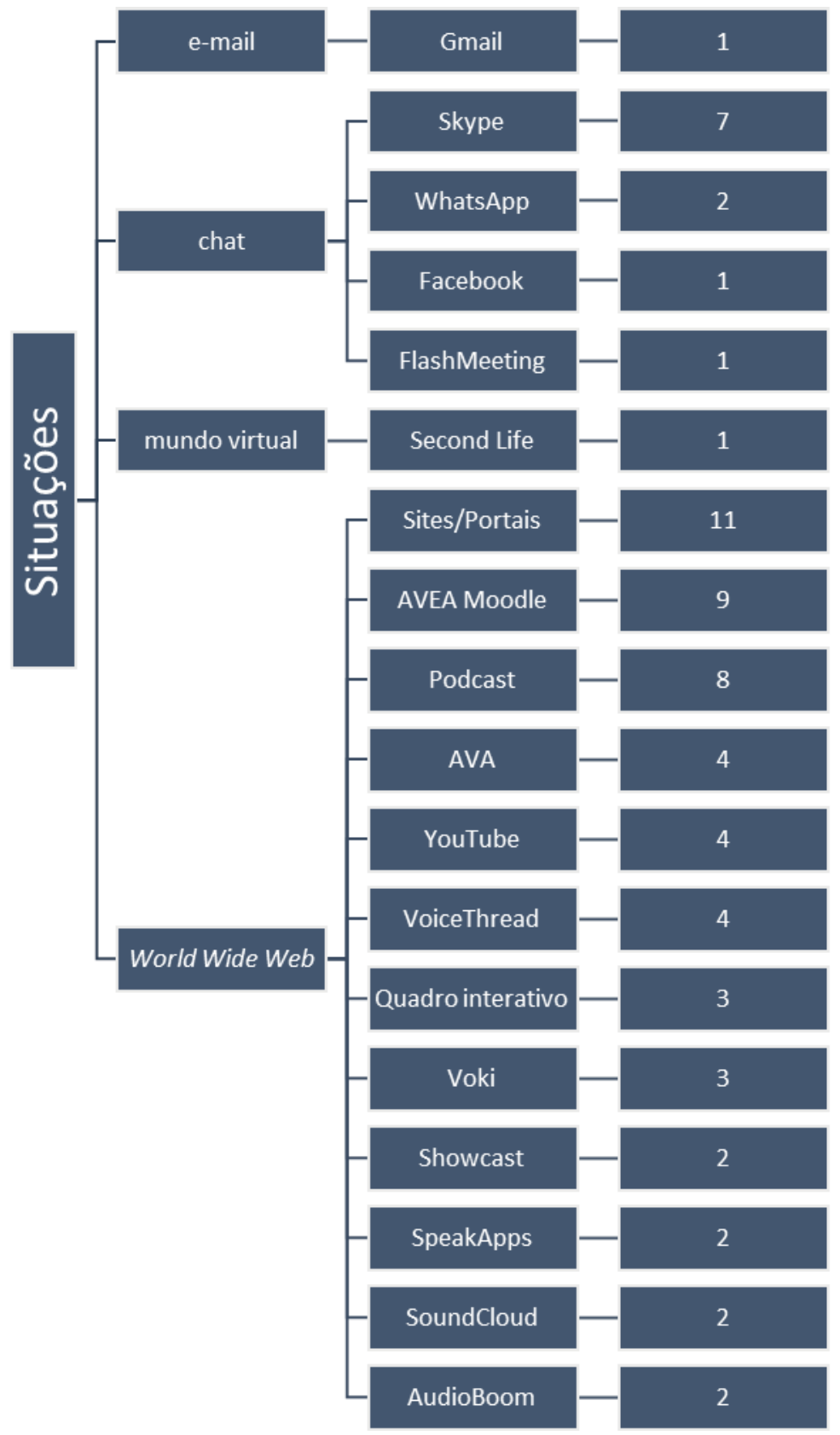

Fonte: dados da pesquisa.

David Crystal (2001, apud MARCUSHI, 2010, p. 19) considera que "o impacto da internet é menor como revolução tecnológica do que como revolução dos modos sociais de interagir linguisticamente". Ao categorizar as tecnologias utilizadas nos trabalhos, percebemos que tal categorização é de fato problemática devido a constantes mudanças de interações sociais ocasionadas pela atualização das tecnologias. As mídias se fundem constantemente, do mesmo modo que al- 
guns aplicativos e programas tratados no corpus desta pesquisa como pertencentes à Internet, já possuem versões offline.

A preferência pela abordagem sociocognitivista-comunicativa, 94,6\% dos trabalhos analisados, como veremos a seguir, demonstra a diversidade de enfoques metodológicos (BERDUGO, 2001), na qual a habilidade oral é vista como tão essencial no processo de comunicação em LE quanto as outras habilidades e a aprendizagem se dá através da interação e por descobrimento, desenvolvendo também a autonomia dos estudantes.

Quadro 7 - Tipos de abordagens (BERDUGO, 2001)

\begin{tabular}{|l|l|l|}
\hline Abordagens & Português & Inglês \\
\hline condutista-estruturalista & 1 & \\
\hline cognitivista-comunicativa & & 2 \\
\hline sociocognitivista-comunicativa & 36 & 17 \\
\hline
\end{tabular}

Fonte: dados da pesquisa.

Há um significativo interesse no enfoque colaborativo baseado em tarefas, com amplo uso dos recursos da Internet, indicando que o ambiente digital é fértil em possibilidades de interação entre os participantes e fontes de informação e de trabalhos com gêneros discursivos - consolidados e emergentes. No artigo de Paiva (2018), por exemplo, os dados foram gerados, entre outros, através de tarefas comunicativas, utilizando-se de uma considerável diversidade de ferramentas digitais, como Moodle, fórum, Vocaroo, Voki, UTellStory, PowToon, Fotobabble, VoiceThread, AudioBoom, mobilizando variados gêneros discursivos. O enfoque baseado em tarefas também é explorado no trabalho de Duarte, Meirinhos e Osório (2011), observado nas implicações dos trabalhos de Furtoso (2011) e Hopkins (2010), e nos resultados de Rocha (2018), que aponta a necessidade de metodologias mais adequadas aos cursos Cursos Virtuais Abertos e Massivos (MOOCs) que viabilizem uma aprendizagem colaborativa e padrões interativos menos controlados.

Observamos que as perspectivas do uso de tecnologias se encontram proporcionalmente equiparadas em pesquisas em língua portuguesa e em língua inglesa, sendo a junção das perspectivas Tecnologista (T) e Social Pragmática (SP) a mais frequente, como vemos na tabela a seguir.

Quadro 8 - Perspectivas do uso das tecnologias segundo Chapelle (2003).

\begin{tabular}{|c|c|c|c|c|c|}
\hline \multirow{2}{*}{$\begin{array}{l}\text { Perspectivas do uso das } \\
\text { tecnologias }\end{array}$} & \multicolumn{2}{|c|}{ Português } & \multicolumn{2}{|c|}{ Inglês } & \multirow[b]{2}{*}{ \% Total } \\
\hline & $\mathrm{N}^{\circ}$ & $\%$ & No & $\%$ & \\
\hline Tecnologista $(\mathrm{T})$ & 8 & $21 \%$ & 5 & $26 \%$ & $23 \%$ \\
\hline Social pragmática (SP) & 4 & $11 \%$ & 3 & $16 \%$ & $13 \%$ \\
\hline Crítica analista (CA) & & & & & \\
\hline
\end{tabular}




\begin{tabular}{|l|l|l|l|l|l|}
\hline $\mathrm{T}+\mathrm{SP}$ & 18 & $49 \%$ & 8 & $42 \%$ & $47 \%$ \\
\hline $\mathrm{T}+\mathrm{SP}+\mathrm{CA}$ & 7 & $19 \%$ & 3 & $16 \%$ & $18 \%$ \\
\hline
\end{tabular}

Fonte: dados da pesquisa.

O principal foco das pesquisas se volta para a utilização em si das TICs pelos alunos e a interação aluno-aluno, aluno-TIC e aluno-professor. A perspectiva crítica analista é evidenciada pela visão de linguagem como prática social, ou seja, desenvolvimento de multiletramentos e trabalho com textos multimodais para se intervir na realidade. Nota-se, porém, que as pesquisas que defendem uma abordagem crítica no uso das tecnologias em seus referenciais teóricos não a apresentam efetivamente nas tarefas de produção oral a serem desenvolvidas, focando os estudos exclusivamente nos aspectos formais, articulatórios, e técnicos necessários para a inclusão digital, não abordando, por exemplo, a interculturalidade através da oralidade. No estudo de Estivalet e Hack (2011) por exemplo, a abordagem crítica está bem clara no referencial teórico, mas não passa daí. Na análise a criticidade é esquecida em prol de aspectos constituintes da linguagem e técnicos. A conexão entre tecnologia e ideologias culturalmente vinculadas, como propõe Chapelle (2003), é ainda pouco estudada no que diz respeito ao ensino-aprendizagem de LE, apontando uma perspectiva predominantemente neutra tanto do uso da tecnologia quanto das práticas discursivas em LE. Isso é um fato preocupante uma vez que todos os discursos são situados socio-culturalmente e o uso neutro da tecnologia, elemento tão presente em nossos dias, é indicador de um ensino tecnicista em que se ensina a língua sem se pensar sobre os discursos. A tabela a seguir expõe quais elementos da habilidade oral foram mais explorados.

Quadro 9 - Aspectos da produção oral.

\begin{tabular}{|c|c|c|c|c|c|}
\hline Aspectos da Produção Oral & Por & guês & Ing & & \\
\hline & No & $\%$ & No & $\%$ & $\%$ Total \\
\hline Cognitivos & 16 & $43 \%$ & 11 & $58 \%$ & $48 \%$ \\
\hline Pragmáticos & 20 & $54 \%$ & 8 & $42 \%$ & $50 \%$ \\
\hline Culturais/Críticos & 1 & $3 \%$ & & & $2 \%$ \\
\hline
\end{tabular}

Fonte: dados da pesquisa.

Entre os aspectos cognitivos da produção oral, destacam-se a fluência, a acurácia, desenvolvimento das estratégias metacognitivas e a motivação. Aqui, evidencia-se o uso de ferramentas de comunicação assíncronas. Os aspectos pragmáticos voltam-se majoritariamente ao estudo da interação de aluno-professor e aluno-aluno, excluindo a interação que poderia ser estabelecida com outros participantes na internet, considerando que a maior parte das atividades foram propostas na World Wide Web. A interação intercultural não é o foco a ser pesquisado nos trabalhos, mesmo no uso de ferramentas de comunicação síncrona estabelecida com falantes nativos, como o teletandem. Esse dado revela que o ensino-aprendizagem da produção oral em LE reproduz estruturas sociais pré-exis- 
tentes por não considerar relevante a mudança de posições do sujeito (KRAMS$\mathrm{CH}, 2017)$. Apenas um trabalho de Rocha (2018), de cunho exploratório, salienta a necessidade de desenvolver a oralidade em Cursos Virtuais Abertos e Massivos (MOOC) sob uma perspectiva educacional crítica.

Os resultados analisados apontam também para uma necessidade de formação docente básica e continuada para o trabalho com a habilidade oral através de TICs, como apontam os trabalhos de Stickler e Shi (2013), Carneiro (2014), Silva (2018), Lima (2013), Cavalcante (2015), entre outros.

\section{Conclusão}

A presente pesquisa se propôs a analisar o que pesquisas recentes sobre o desenvolvimento da habilidade de produção oral através das TICs apontam, identificando quais tecnologias e abordagens de ensino de LE são utilizadas, quais aspectos da oralidade são trabalhados e que restrições e possibilidades são apontadas.

Os dados indicam uma ampla variedade de TICs que podem ser utilizadas para o desenvolvimento da habilidade oral e oferecem a possibilidade de uma prática flexível espacial e temporalmente. Alguns professores recorrem a tecnologias conhecidas como o Gmail - na troca de arquivos de áudio -, o Skype, sites e portais. Vemos, no entanto, que essa preferência se dá no Ensino a Distância, enquanto no semipresencial ou em cursos presenciais há predileção por outras ferramentas, tais como Voicethread, YouTube e Podcasts, que exigem o letramento adequado, embora trabalhando gêneros conhecidos pela comunidade. Os multiletramentos são desenvolvidos predominantemente a partir da aprendizagem colaborativa, sendo possível relacionar então o enfoque sociocognitivo-comunicativo à perspectiva do uso de tecnologias predominantemente tecnologista $\mathrm{e}$ social-pragmática. A perspectiva intercultural dos letramentos através da oralidade não é de fato explorada, indicando uma lacuna de pesquisa, uma vez que não encontramos nenhuma pesquisa que trabalhasse essa perspectiva para além do referencial teórico e a levasse para a prática. Apesar da maioria das pesquisas enfatizarem a necessidade de formação de professores adequada ao uso das TICs para o desenvolvimento da habilidade oral, não encontramos nenhuma pesquisa cujo objetivo seja o de preparar futuros docentes. $\mathrm{O}$ foco demonstrado nos potenciais tecnológicos pode, possivelmente, levar à convicção de que os alunos de licenciatura, ao desenvolverem as habilidades técnicas para o uso dos recursos apontados, serão capazes de aplicá-los futuramente. Essa visão, porém, é limitante, visto que a tecnologia evolui rapidamente e novos letramentos serão necessários. Essa talvez seja a principal lacuna que esta pesquisa aponta, pois, como propõe Siemens (2004), temos que capacitar professores a aprender como lidar com essa fluidez típica do ambiente digital. A consequência de não termos uma quantidade significativa de professores formados para as necessidades da atualidade restringe suas possibilidades de atuação profissional e pode impactar negativamente a sociedade como um todo, visto que os letramentos necessários 
para a participação social na era digital precisam ser desenvolvidos com e pelos os professores de forma a não contribuir com desigualdades sociais (KUMARAVADIVELU, 2001). Vimos na descrição dos dados que a $\mathrm{EaD}$ é área que tem mais estudos em língua portuguesa sobre tecnologia; porém, ainda a perspectiva tecnologista-pragmática sobrepõe-se a uma abordagem mais profunda do contexto e das ideologias vinculadas culturalmente. Possivelmente essa seja uma consequência da ausência de uma formação crítica da educação básica e de professores formadores no que diz respeito à língua e à cultura estrangeira. As implicações deste trabalho se dão iluminar o panorama de pesquisas sobre o ensino da oralidade através de TICs, relacionando essas pesquisas com alguns preceitos teóricos sobre ensino e TICs.

O estudo também aponta algumas lacunas de pesquisa na área de ensino -aprendizagem de LE no que diz respeito (1) ao desenvolvimento da habilidade oral através das TICs dentro de uma perspectiva intercultural e crítica, (2) à área de formação básica e continuada de professores de LE no desenvolvimento da produção oral com TICs e (3) ao trabalho com tecnologias que contemplem ambos os tipos de comunicação - síncrona e assíncrona - assim como as habilidades integradas. Esperamos que com essa análise sistemática de pesquisas na área possamos contribuir para que novas pesquisas que investiguem alguns elementos apontados como lacuna nos estudos sobre ensino de LE através de TICs.

\section{Notes}

1. Neste artigo os termos produção oral, expressão oral, interação oral e oralidade são compreendidos como sinônimos de habilidade oral produtiva, não havendo enfoque na habilidade de compreensão oral receptiva.

2. De acordo com Morosov e Martinez (2008, p. 23-24), "A abordagem é um conjunto de crenças, pressupostos e princípios de um conceito de língua, de ensinar e aprender uma língua estrangeira [...]" enquanto no método, que é mais restrito e específico, "o professor segue uma sequência de técnicas que, se fossem aplicadas 'corretamente' e seguidas à risca, fariam com que os resultados da aula fossem atingidos."

\section{Referências}

ANÇÃ, Maria Helena. Da Língua Materna à Língua Segunda. Noesis, nº 51, 1999, p. $14-16$

AUSTIN, J. L. Quando dizer é fazer. Porto Alegre: Artes Médicas, 1990. 211p.

BERDUGO, M. (2001). Integración de tecnologias multimedia em la enseñanza de lenguas. In: Revista Lenguaje no 28. Pp. 84-107.

CASTRO, A. A. Revisão sistemática e meta-análise. 2001. Disponível em: http:// metodologia.org/wp-content/uploads/2010/08/meta1.PDF; acesso em 14 dez. 2018.

CELANI, M. A. A. Ensino de línguas estrangeiras: ocupação ou profissão?. In: LEFFA, V. J. et al. O Professor de Línguas Estrangeiras: construindo a profissão. 2. ed. Pelotas: EDUCAT, 2008, p. 23-43.

CHAPELLE, C. English Language Learning and Technology. Amsterdam/Philadelphia: John Benjamins Publishing Company, 2003. 
CRYSTAL, D. Language and the Internet. 1 ed. Cambridge: Cambridge University Press, 2001.

DE-LA-TORRE-UGARTE-GUANILO, M. C.; TAKAHASHI, R. F.; BERTOLOZZI, M. R. Revisão sistemática: noções gerais. Revista da Escola de Enfermagem USP, São Paulo, v. 45, n. 5, p. 1260 - 1266, out. 2011.

HYMES, D. H. On Communicative Competence. In: PRIDE, J. B.; HOLMES, J. Sociolinguistics. Baltimore, USA: Penguin Education, Penguin Books Ltd, 1972, p.269-293.

KERN, R; WARSCHAUER, M. Introduction: theory and practice of network-based language teaching. Cambridge: Cambridge University Press, 2000.

KRAMSCH, C. Cultura no ensino de língua estrangeira. Tradução de Orison Marden Bandeira de Melo Júnior. Bakhtiniana, São Paulo, 2017.

KRASHEN, S. The Input Hypothesis: issues and implications. 4.ed. New York: Longman, 1985.

KUMARAVADIVELU, B. Toward a postmethod pedagogy. TESOL Quarterly, 35, 2001, 537-560.

LEFFA, V. J. Ensino de línguas: passado, presente e futuro. Revista de Estudos da Linguagem. Vol. 20, n. 2, p. 389-411, jul/dez. 2012.

LEVELT, W. J. M. Speaking: From intention to articulation. Cambridge, MA: MIT Press, 1989.

LEVELT, W. A Blueprint of the speaker. In: BROWN, C.; HAGOORT, P. The neurocognition of language. Oxford: Oxford Press, 1999, 83-122.

LEVY, M. Computer-Assisted Language Learning: Context and conceptualization. Oxford: Clarendon Press, 1997.

LEVY, M; HUBBARD, P. Why call CALL "CALL"?. Computer Assisted Language Learning, vol. 18, n. 3, p. 143 - 149, jul. 2005.

MARCUSCHI, L. A. Gêneros textuais emergentes no contexto da tecnologia digital. IN: MARCUSCHI, L. A.; XAVIER, A. C. (Orgs.) Hipertexto e gêneros digitais. São Paulo: Cortez, 2010, p. 15-80.

MARTINS, C.M.M.J.; MOREIRA, H. O campo CALL (Computer Assisted Language Learning): definições, escopo e abrangência. Calidoscópio, vol. 10, n. 3, p. 247255, set/dez 2012.

MUÑOZ, C.; ARAÚJO, L.; CEIA, C. Aprender uma segunda língua. $1^{\text {a }}$ ed. Lisboa: Fundação Francisco Manuel dos Santos, 2011.

PREUSS, E. O. Habilidade oral em L2: da cognição à interação. Horizontes de Linguística Aplicada, Brasília, n. 2, p. 167-186, jan. 2014.

RICHARDS, J. C. \& RODGERS. Approaches and Methods in Language Teaching. Cambridge: Cambridge University Press, 1986.

RODRIGUES, R. H.; CERUTTI-RIZZATTI, M. E. Linguística Aplicada: ensino de língua materna. Florianópolis: LLV/CCE/UFSC, 2011.

RODRIGUES, R. R.; ORTIZ-PREUSS, E. Habilidade oral em L2: percepções de docentes e discentes. Odisseia, Natal, v. 2, n. 1, p. 72-92, jan. 2017.

SIEMENS, G. Connectivism: A Learning Theory for the Digital Age. 2004. Disponível $\mathrm{em}<\mathrm{http}: / / \mathrm{www}$.elearnspace.org/Articles/connectivism.htm>. Acesso em 20 maio 2019. 
SWAIN, M. Communicative competence: Some roles of comprehensible input and comprehensible output in its development. In S. Gass \& C. Madden (Eds.), Input in second language acquisition (pp. 235-253). Rowley, MA: Newbury House, 1985.

WALKER, A.; WHITE, G. Technology Enhanced Language Learning. 1 ed. Oxford: Oxford University Press, 2013.

Recebido em: 11/07/2019

Aceito em: 09/12/2019 


\section{APÊNDICE}

\section{Trabalhos em língua portuguesa analisados}

1. ANTUNES, Cláudia Rafaela Neto de Azevedo. Mudam-se os tempos, mudam-se os gadgets: Voki, uma proposta de trabalho da expressão oral no ensino das línguas. 2012. Dissertação (Mestrado em Ensino de Português e de Espanhol no 3. ${ }^{\circ}$ Ciclo do Ensino Básico e no Ensino Secundário) - Universidade do Minho, [S. l.], 2012.

2. ARANDA, Maria del Carmen de la Torre. Interações orais online no ensino do francês língua estrangeira: o projeto Cefradis. 2011. Tese (Doutorado em Língua e Literatura Francesa) - Faculdade de Filosofia, Letras e Ciências Humanas, Universidade de São Paulo, São Paulo, 2011. doi:10.11606/T.8.2011.tde24082011-141810. Acesso em: 2019-12-14.

3. CALDAS, Vaneska Oliveira. A tecnologia digital móvel em uma abordagem híbrida: o papel do feedback no desenvolvimento da produção oral em inglês como L2. 2018. 224f. Dissertação (Mestrado em Estudos da Linguagem) - Centro de Ciências Humanas, Letras e Artes, Universidade Federal do Rio Grande do Norte, Natal, 2018.

4. CARNEIRO, Maria Elsa Moreira. A oralidade em língua estrangeira, TIC e ambientes interativos de aprendizagem: aporias e limitações. 2014. Dissertação (Mestrado em Didática das Línguas Materna ou Estrangeiras e Supervisão Pedagógica em Línguas) - Universidade do Porto, 2014.

5. CAVALCANTE, Luciana Rocha. A oralidade no ensino de Línguas Estrangeiras nos cursos de Licenciatura em Letras a distância. In: CONAHPA, 7., 2015, São Luiz. Hipermídia e Interdisciplinaridade na geração de conhecimento. São Luiz: CCE/UFSC, 2015. p. 1 - 11.

6. CAVALCANTE, Luciana Rocha. A oralidade nos cursos a distância de licenciatura em Letras com habilitação em língua portuguesa: uma análise discursiva. 2011. 218 f. Tese (doutorado) - Universidade Estadual Paulista, Faculdade de Ciências e Letras de Araraquara, 2011.

7. COUVANEIRO, Sílvia; PEDRO, Neuza. Desenvolver a oralidade na aula de inglês com recurso a tecnologias móveis - projeto de vídeo com iPad. In Gomes, M. J., Osório, A. J., \& Valente, L. (orgs.), Atas da IX Conferência Internacional de TIC na Educação - Challenges 2015 - Meio Século de TIC na Educação (pp. 267-279). Braga: Universidade do Minho. Centro de Competência em TIC na Educação. 
8. DOURADO, Luciana Brandão. O trabalho com a oralidade em um curso de licenciatura em língua espanhola (EAD): realidades e necessidades. 2016. 138 f., il. Dissertação (Mestrado em Linguística Aplicada) - Universidade de Brasília, Brasília, 2016.

9. DUARTE, Luís; MEIRINHOS, Manuel; OSÓRIO, António (2011). A utilização da aplicação online VoiceThread como complemento à aula de inglês. In Conferência Ibérica: Inovação na Educação com TIC. Bragança: Instituto Politécnico de Bragança. p. 175-188. ISBN 978-972-745-120-3

10. ESTIVALET, Gustavo Lopez; HACK, Josias Ricardo. Ensino da oralidade em Língua Estrangeira na EaD através de programas de comunicação síncrona. Revista Eletrônica de Educação, [s. l.], v. 8, ed. 3, p. 164-181, 2014. DOI http:// dx.doi.org/10.14244/19827199784.

11. ESTIVALET, Gustavo Lopez; HACK, Josias Ricardo. Ensino de língua estrangeira a distância: reflexões sobre o ensino-aprendizagem da habilidade oral. Anais do VII Congresso Internacional da ABRALIN, CD-ROM. Curitiba/PR, 2011.

12. FADINI, Karina Antonia. VOICETHREAD NA PRODUÇÃO ORAL DE INGLÊS COMO L2. In: CONEL, 2., 2013, Vitória. Anais do II CONEL. Vitória: 2014. p. $61-63$.

13. FALCÃO, Carla Aguiar. Produção oral em espanhol como L2 e educação a distância: diálogos e práticas possíveis. 2016. 220f. Tese (Doutorado em Estudos da Linguagem) - Centro de Ciências Humanas, Letras e Artes, Universidade Federal do Rio Grande do Norte, Natal, 2016.

14. FARIA, Elaine Risques. $\mathrm{O}$ uso do hipertexto na aula de língua inglesa: promovendo o desenvolvimento da oralidade por meio de novas práticas de linguagem. 2012. 101 f. Dissertação (Mestrado em Ciências Humanas) - Universidade Federal de São Carlos, São Carlos, 2012.

15. FARIA, Helen de Oliveira. A compreensão e a produção oral em língua inglesa no meio virtual sob a visão dos multiletramentos. Revista Moinhos, Tangará da Serra, v. 4, ed. 4, 2014.

16. FORGIARINI DE QUADROS, Gerson Bruno. PRODUÇÃO DE DESENHOS ANIMADOS NA ESCOLA: LETRAMENTOS E MULTIMODALIDADE NO ENSINO E APRENDIZAGEM DE IDIOMAS. Anais do Encontro Virtual de Documentação em Software Livre e Congresso Internacional de Linguagem e Tecnologia Online, [S.l.], v. 1, n. 1, dez. 2012. 
17. FRANGO, Florência Robalo Basílio (2012) - Desenvolvimento da competência comunicativa: a oralidade do francês com as TIC. Castelo Branco: IPCB. Escola Superior de Educação. 96 f. Dissertação de Mestrado.

18. FURTOSO, Viviane Bagio; GOMES, Maria João. Aprendizagem e avaliação da oralidade em contextos online: o potencial dos serviços de podcasting. AVALIAÇÃO DAS APRENDIZAGENS EM AMBIENTES FORMAIS, "VIRTUAIS" E A DISTÂNCIA, Braga, 6 nov. 2011.

19. FURTOSO, Viviane Aparecida Bagio. Desempenho oral em português para falantes de outras línguas: da avaliação à aprendizagem de línguas estrangeiras em contexto online. 2011. 283 f. Tese (doutorado) - Universidade Estadual Paulista, Instituto de Biociências, Letras e Ciências Exatas, 2011.

20. FURTOSO, Viviane Bagio; GOMES, Maria João; CONSOLO, Douglas Altamiro. Os serviços de podcasting na otimização da aprendizagem e da avaliação de língua estrangeira em contexto online. In: VII CONFERêNCIA INTERNACIONAL DE TIC NA EDUCAÇÃO, 7., 2011, Braga. Perspetivas de Inovação. Braga: Centro de Competência da Universidade do Minho, 2011. p. 767 - 781.

21. GARCIA, Hugo Boleixa. O uso dos quadros interativos multimédia e o desenvolvimento das competências de oralidade no ensino de inglês e espanhol. 2016. Dissertação (Mestrado em Ensino de Inglês e Espanhol nos Ensinos Básico e Secundário) - Universidade Nova de Lisboa, [S. l.], 2016.

22. HASHIGUTI, Simone Tiemi. Reflexões sobre corpora de pesquisa discursiva e produção oralem aprendizagem de língua inglesa como LE na modalidade adistância. Domínios de Lingu@gem, [s. l.], v. 9, ed. 5, p. 410-423, 2015.

23. LEÃO, Murillo Jaime. Produção de vídeos em língua espanhola: o whatsapp como meio de interação. 2018. Artigo (especialização) - Universidade Federal de Santa Maria, Centro de Artes e Letras, Curso de Especialização em Tecnologias da Informação e da Comunicação Aplicadas à Educação, EaD, RS, 2018.

24. LIMA, Samuel de Carvalho. Uso de tecnologias digitais para o Ensino a Distância da compreensão e produção oral em língua inglesa por computador/WEB. Rev. bras. linguist. apl., Belo Horizonte, v. 13, n. 3, p. 853-876, Sept. 2013. http:// dx.doi.org/10.1590/S1984-63982013005000010.

25. LOPES, Diana Vasconcelos; BARBUIO, Eduardo; SILVA, Layanne Roberta de Araújo. APRENDIZAGEM DE INGLÊS MEDIADA POR COMPUTADOR EM SITES GRATUITOS: A ORALIDADE EM FOCO. Pedagogia em foco, Iturama, v. 11, ed. 5, 2016. 
26. LOPES, Émile Paz. A interação via SKYPE no ensino de línguas em EaD. 2012. Trabalho de Conclusão de Curso (Especialização em Tecnologias da Informação e da Comunicação Aplicadas à Educação) - Universidade Federal de Santa Maria, Centro de Artes e Letras, RS, 2012.

27. MARMELEIRA, Ana Maria; NOBRE, Ana Maria. O PRESENTE DIGITAL: O USO DE PODCASTS E DE SHOWCASTS. In: II CONGRESSO INTERNACIONAL TIC E EDUCAÇÃO, 2., 2012, Lisboa. Em direção à Educação 2.0. Lisboa: Instituto de Educação da Universidade de Lisboa, 2012. p. 1693 - 1703.

28. NOBRE, Ana; CARDOSO, Teresa. Educação online e línguas estrangeiras: ferramentas digitais gratuitas para desenvolver a oralidade em francês. Indagatio Didactica, Aveiro, v. 7, ed. 1, 2015.

29. OlIVEIRA, Robson Azevedo Costa; SANTOS, Rita de Cássia Cardoso dos. EDUCAÇÃO A DISTÂNCIA: METODOLOGIA DO ENSINO DE LÍNGUAS EM PRÁTICAS DE INTERAÇÃO ORAL NO CURSO DE LICENCIATURA EM LÍNGUA ESPANHOLA. In: 11 ENFOPE/12 FOPIE, 11., 2018, Aracaju. Anais do 11 ENFOPE/12 FOPIE. Aracaju: 2018. p. 1 - 15.

30. PAIVA, Vera Lúcia Menezes de Oliveira. Tecnologias digitais para o desenvolvimento de habilidades orais em inglês. DELTA [online]. 2018, vol. 34, n.4, pp. 1319-1351. ISSN 0102-4450. http://dx.doi.org/10.1590/0102445008554706004546.

31. REIS, Susana Cristina dos. Ensino de produção oral em língua inglesa por meio de podcast: relatando uma experiência com alunos do ensino fundamental. Veredas On-line: As Tecnologias Digitais no Ensino e Aprendizagem de Línguas, Juiz de Fora, v. 21, ed. 1, p. 180-201, 2017.

32. ROCHA, Cláudia Hilsdorf. CURSOS VIRTUAIS ABERTOS E MASSIVOS EM LÍNGUA ESTRANGEIRA: REFLEXÕES SOBRE DESIGN E PRODUÇÃO ORAL EM CONTEXTOS DIGITAIS DE APRENDIZAGEM. Revista de Letras Norte@mentos: Formação de Professores e Ensino, Sinop, v. 11, ed. 27, p. 32-52, 2018.

33. SANTOS, Karina Fernandes dos. Experimentação em TICs: reflexões para a prática da oralidade no ensino de L.E. em Ambiente Virtual de Aprendizagem (AVA). 2013. xiv, 187 f., il. Dissertação (Mestrado em Linguística Aplicada) - Universidade de Brasília, Brasília, 2013.

34. SANTOS, Cíntia Pereira dos. Ensino de fonética da língua inglesa com uso de material digital. 2016. Dissertação (Mestrado em Ensino de 
Ciências Humanas, Sociais e da Natureza) - Universidade Tecnológica Federal do Paraná, Londrina, 2016.

35. SELVERO, Caroline Mitidieri; PADILHA, Emanuele Coimbra. Escrita e oralidade: interação mediada pela tecnologia. In: V CONGRESO INTERNACIONAL DE LETRAS, 5., 2012, Buenos Aires. Transformaciones culturales. Buenos Aires: UBA, 2012.p. 0781 - 0786.

36. SILVA, Paulo Bruno Lopes da. Práticas de expressão oral em Francês Língua Estrangeira a distância: desenvolvimento da fluência oral e da fluência digital em um curso on-line. 2018. Dissertação (Mestrado em Língua e Literatura Francesa) - Faculdade de Filosofia, Letras e Ciências Humanas, Universidade de São Paulo, São Paulo, 2018. doi:10.11606/D.8.2018. tde-23072018-165812. Acesso em: 2019-12-14.

37. SOUSA, Lorena Azevedo de.; WEISSHEIMER, Janaína. A ferramenta VoiceThread em uma abordagem híbrida: o desenvolvimento da produção oral de aprendizes de inglês como L2. Linguagem \& Ensino (UCPel. Impresso), v. 1, p. 1, 2014.

\section{Trabalhos em língua inglesa analisados}

1. AFSHARI, Sajad; KETABI, Saeed. CURRENT TRENDS AND FUTURE DIRECTIONS IN TEACHING ENGLISH PRONUNCIATION. International Journal of Research Studies in Language Learning, [s. l.], v. 6, ed. 2, p. 83-91, 2017.

2. APPEL, Christine et al. SpeakApps 2: Speaking Practice in a Foreign Language through ICT Tools. In: EUROCALL CONFERENCE, 21., 2014, Groningen. Proceedings of the 2014 EUROCALL Conference. Dublin: Research-publishing.net, 2014. p. 12 - 17.

3. CHEISHVILI, Sophio. The Development of and the Effect of Electronic Speaking Portfolios on Learners' Academic Performance in English as a Foreign Language Classes in Primary School. Journal of Education in Black Sea Region, [ $s$. l.], v. 4, ed. 1, p. 83-91, 2018.

4. COUTO, Sabela Melchor. Second life: Anxiety-free language learning? In: ICT FOR LANGUAGE LEARNING, 3., 2010, Florença. Proceedings of the International Conference ICT for Language Learning, 3rd Edition 2010. Florença: Simonelli Editore - University Press, 2010. 
5. GROMIK, Nicolas A. Cell phone video recording feature as a language learning tool: A case study. Computers \& Education, [s. l.], v. 51, ed. 1, p. 223-230, 2012.

6. ISTIFCI, Ilknur; LOMIDAZDE, Tamar; DEMIRAY, Ugur. An effective role of e-learning technology for English Language Teaching by using meta communication actors. Turkish Online Journal of Distance Education, [s. l.], v. 12, ed. 4, 2011.

7. LU, Zhihong; HOU, Leijuan; HUANG, Xiaohui. A research on a studentcentred teaching model in an ICT-based English audio-video speaking class. International Journal of Education and Development using Information and Communication Technology (IJEDICT), [s. l.], v. 6, ed. 3, p. 101-123, 2010.

8. MASRUDDIN, Masruddin. The Efficacy of Using Short Video Through Group Work in Teaching Speaking to Indonesian English As Foreign Language (EFL) Students. Arab World English Journal , [s. l.], v. 9, ed. 3, p. 282-293, 2018.

9. NGUYEN, Thi-Huyen; HWANG, Wu-Yuin; PHAM, Xuan-Lam; MA, Zhao -Heng. User-Oriented EFL Speaking through Application and Exercise: Instant Speech Translation and Shadowing in Authentic Context. Educational Technology \& Society, [s. l.], v. 21, p. 129-142, 2018.

10. PARDO, Betlem Soler. Digital Storytelling: A Case Study of the Creation and Narration of a Story by EFL Learners. Digital Education Review, [s. l.], v. 26, p. 74-84, 2014.

11. PARDO, Betlem Soler. Skype ${ }^{\text {mi }}$ Conference Calls: A Way to Promote Speaking Skills in the Teaching and Learning of English. PROFILE, Bogotá, v. 17, ed. 1, p. 143-156, 2015.

12. PARRA SUAREZ, Fredy Guillermo. Creating Connections: The Impact of Self-assessment Strategies and Technology in Speaking Accuracy. 2018. Dissertação (Master in English Language Teaching Autonomous Learning Environments) - Universidad de La Sabana, Chía, 2018.

13. POP, Anisoara. The impact of the new technologies in foreign language instruction our experience. Procedia - Social and Behavioral Sciences, [s. l.], v. 2, ed. 2, p. 1185-1189, 2010.

14. SOKOLI, Stavroula. ClipFlair: Foreign Language Learning through Interactive Revoicing and Captioning of Clips. In Subtitles and Language Learning, [s. l.], p. 127-147, 2015. 
15. SOKOLI, Stavroula. Distance language learners' perceptions of assessed, student-led speaking tasks via a synchronous audiographic conferencing tool. Innovation in Language Learning and Teaching, [s. l.], v. 4, ed. 3, p. 235-258, 2010.

16. STICKLER, Ursula; SHI, Lijing. Supporting Chinese speaking skills online. System, [s. l.], v. 41, ed. 1, p. 50-69, 2013.

17. SUN, Yu-Chih. Examining the effectiveness of extensive speaking practice via voice blogs in a foreign language learning context. Calico Journal , [s. l.], v. 29, ed. 3, p. 494-506, 2012.

18. SYSOYEV, P.V. PODCASTS IN TEACHING A FOREIGN LANGUAGE. Language and Culture, Tomsk, v. 2, p. 139-150, 2014.

19. TAN, Yuh-Huann; TAN, Seng-Chee. A Metacognitive Approach to Enhancing Chinese Language Speaking Skills With Audioblogs. Australasian Journal of Educational Technology, Melbourne, v. 16, ed. 7, p. 1075-1089, 2010. 